findings with the capillaroscopic patterns (early, active, and late, according to Cutolo's classification (2))

Methods: we recruited 125 SSc patients (M/F: 14/111, mean age 55+/-12.7 years, median disease duration 11 years) in 3 Rheumatology Centres in Sicily, Italy, from January to December 2019.

Transthoracic echocardiogram with aortic root diameter measurement was carried out in all patients. Moreover, videocapillaroscopy with identification of early, active, or late SSc patterns was performed in the whole case series. Patients with early SSc pattern formed the subgroup 1, while those with the active or late patterns (both characterized by the reduction of capillary density) the subgroup 2.

Results: we identified 8 (6.4\%) SSc patients with aortic root dilation (diameter > $35 \mathrm{~mm}$ ). Their age and their frequencies of cardiovascular risk factors were similar to the whole series. Moreover, videocapillaroscopy showed $62(49.6 \%)$ early, $47(37.6 \%)$ active, and $16(12.8 \%)$ late SSc patterns.

Aortic root dilation was observed in only one patient in the subgroup $1(1 / 62$, $1.6 \%)$, and in 7 cases of the subgroup $2(7 / 63,11.1 \%) ; p=0.03$.

Conclusion: in this multicentre study, we found that aortic root dilation is significantly associated with the reduction of capillary density at nailfold capillaroscopy (active or late SSc patterns). On the basis of these findings, we might argue that SSc-related microangiopathy of vasa vasorum could contribute to aortic wall damage, at least in a subset of SSc patients.

References:

[1] Bartoloni E, Pucci G, Cannarile F, Battista F, Alunno A, Giuliani M, Cafaro G, Gerli R, Schillaci G. Central hemodynamics and arterial stiffness in systemic sclerosis. Hypertension 2016; 68:1504-1511. 2.Cutolo M, Matucci-Cerinic M. Nailfold capillaroscopy and classification criteria for systemic sclerosis. Clin Exp Rheumatol 2007; 25:663-665

Disclosure of Interests: Michele Colaci: None declared, Ylenia Dal Bosco: None declared, Claudia Schinocca: None declared, Maria Letizia Aprile: None declared, Giuliana Guggino Grant/research support from: Pfizer, Celgene, Speakers bureau: Celgene, Sandoz, Pfizer, Ilenia De Andres: None declared, Alessandra Azzurra Russo: None declared, Gianluca Sambataro: None declared, Domenico Sambataro: None declared, Lorenzo Malatino: None declared DOI: 10.1136/annrheumdis-2020-eular.3156

\section{AB0564 HEART VALVULAR ALTERATIONS IN A MULTICENTRE ITALIAN COHORT OF SSC PATIENTS}

M. Colaci ${ }^{1}$, C. Schinocca ${ }^{2}$, Y. Dal Bosco3, M. L. Aprile3, G. Guggino ${ }^{4}$, I. De Andres ${ }^{5}$, A. A. Russo ${ }^{5}$, D. Sambataro ${ }^{1}$, G. Sambataro ${ }^{1}$, L. Malatino ${ }^{1}$. ${ }^{1}$ University of Catania, Catania, Italy; ${ }^{2}$ Rheumatology Centre, Ospedale Cannizzaro, Catania, Italy; ${ }^{2}$ Rheumatology Centre, Ospedale Cannizzaro, Catania, Italy; ${ }^{4}$ University of Palermo, Palermo, Italy; ${ }^{5}$ Ospedale Garibaldi Centro, Catania, Italy

Background: systemic sclerosis (SSc) in a chronic autoimmune disease characterized by endothelial dysfunction, diffuse microangiopathy, and fibrosis of skin and visceral organs. Typical cardiac involvement may includes microvascular ischemia, contraction band necrosis, and patchy fibrosis, leading mainly to arrythmias and conduction defects, diastolic dysfunction, or right ventricular failure (secondary to pulmonary arterial hypertension) [1]. Valvular diseases are poorly described and generally not considered a typical sign of SSc [2-4].

Objectives: we aimed to describe valvular alterations in a multicentre cohort of SSc patients.

Methods: we consecutively recruited 118 SSc patients (M/F: 14/104, mean age $56.7 \pm 12.4$ years, median disease duration 10 years, limited/diffuse skin subsets: 95/23, anti-centromere/anti-Scl70/others autoantibodies: 35/37/46) in 3 Rheumatology Centres in Sicily, Italy, from January to December 2019.

Considering the cardiovascular risk factors, 40 (34\%) patients were smokers, 7 $(6 \%)$ diabetics, 12 (10\%) showed hypercholesterolemia, $38(32 \%)$ arterial hypertension, while none was obese. Transthoracic echocardiogram was carried out in all patients during their follow-up.

Results: valvular abnormalities were as follow: mitral valve: insufficiency 85 $(72 \%)$ cases - mild in $77 / 85$, stenosis $2(2 \%)$ - mild in $25 / 28$, sclerosis/tickening $36(30 \%)$, and calcification $9(8 \%)$ patients; aortic valve: insufficiency 28 $(24 \%)$, stenosis $4(3 \%)$, sclerosis $29(25 \%)$, and calcification $7(6 \%)$ patients; tricuspid valve: insufficiency $91(77 \%)$ cases, no cases of stenosis, sclerosis $5(4 \%)$, and calcification $1(1 \%)$ patients; pulmonary valve: insufficiency in 13 (11\%) patients.

As expected, tricuspid insufficiency (TI) was associated with pulmonary arterial hypertension (PAH) (moderate $\mathrm{TI}$ in $20 \%$ of patients with every $\mathrm{TI}$ and $\mathrm{PAH}$ vs. $4 \%$ of patients with $\mathrm{TI}$ without $\mathrm{PAH}, \mathrm{p}=0.019$ ).
Aortic sclerosis (AS) was associated with the presence of arthritis (AS in 35\% of patients with arthritis vs. $16 \%$ of patients without, $p=0.029$ )

No association was found with age, gender, disease duration, skin subset, autoantibodies, capillaroscopic patterns, presence of digital ulcers, lung, renal, or digestive involvements

Conclusion: in this multicentre SSc cohort study, we found that cardiac valve alterations are very common, even though generally not clinically relevant. The presence of PAH was associated with more severe TI. Finally, AS was associated with arthritis that could be considered sign of chronic inflammatory state, which is often linked with accelerated atherosclerosis and remodeling process of aortic valve [5].

\section{References:}

[1] Lambova S. Cardiac manifestations in systemic sclerosis. World J Cardio 2014; 6:993-1005.

[2] D’Angelo W, Fries JF, Masi AT, Shulman LE. Pathologic observations in systemic sclerosis (scleroderma).A study of fifty-eight autopsy cases and fifty-eight matched controls. Am J Med 1969; 46:428-440.

[3] Kazzam E, Caidahl K, Hallgren R, et al. Mitral regurgitation and diastolic flow profile in systemic sclerosis. Int J Cardiol 1990; 29:357-363

[4] Wranicz J, Zielińska M, Cygankiewicz I, et al. Early cardiovascular involvement in patients with systemic sclerosis (SSc). Med Sci Monit. 2002 8:CR78-82.

[5] Coté N, Mahmut A, Bosse $Y$, et al. Inflammation is associated with remodeling of calcific aortic valve disease. Inflammation 2013; 36:573-581.

Disclosure of Interests: Michele Colaci: None declared, Claudia Schinocca: None declared, Ylenia Dal Bosco: None declared, Maria Letizia Aprile: None declared, Giuliana Guggino Grant/research support from: Pfizer, Celgene Speakers bureau: Celgene, Sandoz, Pfizer, Ilenia De Andres: None declared, Alessandra Azzurra Russo: None declared, Domenico Sambataro: None declared, Gianluca Sambataro: None declared, Lorenzo Malatino: None declared

DOI: 10.1136/annrheumdis-2020-eular.4348

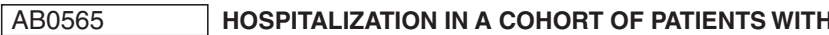 IDIOPATHIC INFLAMMATORY MYOPATHY: WHAT IS HAPPENING IN ARGENTINA?}

F. Arizpe ${ }^{1}$, M. Cosentino ${ }^{1}$, A. C. Costi ${ }^{1}$, V. Martire ${ }^{1}$, A. Testi ${ }^{1}$, M. García ${ }^{1} .{ }^{1}$ HIGA San Martin, La Plata, Argentina

Background: Inflammatory myopathies are rare diseases that affect multiple organs and systems, with poor prognosis and high in-hospital mortality. ${ }^{(1,2)}$ In Argentina there are few reported data regarding hospitalization and its outcomes in these patients.

Objectives: To analyze the characteristics of hospitalizations and the factors associated with poor outcome in adult patients with Idiopathic Inflammatory Myopathy (IIM)

Methods: Retrospective, analytical study. We included patients $\geq 18$ years with IIM, according to Bohan and Peter and/or ACR / EULAR 2017 criteria, who were admitted in our hospital between 2003 and 2019 at least once. Sociodemographic and clinical data were recorded. We defined "unfavorable outcome" as the presence of one of the following events: death, mechanical respiratory assis tance and/or critical care unit requirement. Continuous variables were compared by Student's or Mann Whitney's T test, and categorical variables by Chi ${ }^{2}$ test or Fisher's exact test. Binary logistic regression was performed to identify independent factors associated with an unfavorable outcome.

Results: 61 hospitalizations of 40 patients with IIM were evaluated; $67.5 \%$ of the patients were female $(27 / 40)$, with a mean age of 52.5 years $(S D \pm 13)$. The most frequent reason of admission was for diagnosis (44.3\%) followed by disease activity (31.1\%). In $78.7 \%$ of hospitalizations (48/61) the diagnosis was dermatomyositis. The median of hospitalization days was 14 (IQR 8-30). In 21 out of 61 hospitalizations (34.4\%), an unfavorable outcome was observed, of which $17(80.9 \%)$ ended in death. Respiratory muscle involvement $(p=0.01)$, thrombocytopenia $(p<0.001)$, treatment with intravenous methylprednisolone pulses $(p=0.032)$, Intravenous Immunoglobulin $(p=0.001)$, longer hospitalization ( $=0.001)$ and severe infections $(p=0.001)$ were associated with adverse outcomes. In the multivariate analysis, serious infections (OR: 21.7; IC95 1.77 - 266 $\mathrm{p}=0.016$ ) and the requirement of Intravenous Immunoglobulin (IVIg) (OR: 54.5 IC95 $1.4-214 ; p=0.033$ ) were found to be independently associated with an unfavorable outcome.

Conclusion: IIMs are diseases with high morbidity and mortality rate. In this cohort of hospitalized patients, we found a high percentage of unfavorable outcomes. Seriously ill patients received IVIg more frequently, and severe infections were associated with worse prognosis. 